\title{
Prenatal stress in pigs: impact on growth, behaviour, neuroendocrine and immune functions in the offspring
}

\author{
W. Otten, E. Kanitz and M. Tuchscherer \\ Institute of Behavioural Physiology, Leibniz Institute for Farm Animal Biology (FBN), \\ 18196 Dummerstorf, Germany
}

Studies in different animal models and humans give evidence that stress experienced by pregnant mothers affects foetal development and has long-term consequences on many physiological systems and behaviour in the offspring, thus facilitating the risk for disorders later in life. In farm animals, housing conditions or inadequate management practices during gestation may be potential stressors for the mother, which could affect growth, vitality, health and welfare of the dam and its offspring, and can also have economic implications. This paper gives a survey of results from different studies in pigs on the impact of maternal stress during gestation on growth, behaviour, neuroendocrine and immune functions in the offspring. Different experimental models using either elevated maternal cortisol levels or stress paradigms are introduced and major results are presented. The survey reveals that also in pigs prenatal stress can impair growth and modify immune functions, stress reactivity and behaviour in the offspring. The materno-foetal cortisol regulation is a major determinant of the alterations in the offspring, and mid- and late gestation seems to be sensitive gestational periods of increased vulnerability to prenatal stress. Neuroendocrine and behavioural results indicate that prenatally stressed pigs can express an over-reactive phenotype characterised by an increased HPA axis reactivity, altered emotionality, more fearfulness in a novel environment and disturbed social behaviour. Further research in this area should focus on the potential consequences of prenatal stress in offspring used for breeding as reproductive and behavioural characteristics may be affected in the long-term.

\section{Introduction}

Numerous studies with rodents, non-human primates and humans have shown that stress experienced by pregnant females has long-term consequences on many physiological systems thereby affecting the disease risk of their offspring. Maternal glucocorticoids are major candidates for the mediation of maternal stress to the foetus because they can cross the placental barrier and exert many organisational effects on foetal tissue maturation and differentiation (see reviews by Fowden \& Forhead, 2004; Harris \& Seckl, 2011). Their importance in processes of foetal programming was demonstrated in rats where maternal adrenalectomy prevented the effects of prenatal restraint stress in the offspring, which could be re-established after maternal 
corticosterone substitution (Barbazanges et al., 1996). Gestational stress or elevated maternal glucocorticoids affect foetal development and have long-term effects on, e.g. insulin sensitivity, cardiovascular function, activity of the hypothalamic-pituitary-adrenal (HPA) axis and brain neurotransmitter systems, immune functions and behaviour in the offspring (see reviews by Viltart \& Vanbesien-Mailliot, 2007; Merlot et al., 2008). Detrimental effects of prenatal stress include growth retardation, increased stress sensitivity and enhanced disease risk, which are also important issues in farm animal research. Predominantly during the last decade, research has focussed on prenatal stress in domestic pigs because in intensive pig husbandry, pregnant sows may be frequently exposed to various stressors during gestation. Confined housing, social stress in group housing, inadequate feeding and management practices may potentially impair performance, vitality, health and welfare of sows and offspring, which may also have a considerable economic impact. It is the aim of this article to review the major results derived from different studies on prenatal stress effects in pig offspring. Paradigms used and concordant or inconsistent results are presented in order to better assess the impact of prenatal stress on performance, physiology and behaviour in pig offspring.

\section{Experimental models of prenatal stress in pigs}

Studies on prenatal stress in pigs were conducted to investigate either the effects of different stressors or the impact of elevated maternal cortisol levels during specific periods of gestation on sow and litter characteristics and the performance of offspring, i.e. growth, HPA function, immune function, coping with challenging situations, behavioural abnormalities etc. The most commonly investigated maternal stress models simulate housing or management situations during gestation, which may be stressful for the animals. Repeated temporary restraint of the sow, rough handling, heat stress or social stress induced by repeated mixing with unfamiliar conspecifics were investigated as potential stressors. In these studies, the impact of a specific stressful situation is examined, which, however, activates multiple physiological responses, e.g. of the HPA and sympathetic adrenomedullary system and may be differently perceived by the animals. The magnitude of the maternal stress responses may therefore depend on individual characteristics, previous experiences, behaviour of pen mates and other factors, and may also change over time when repeatedly applied. To examine the specific role of maternal cortisol for prenatal stress effects and to better standardize the maternal stress reaction, other approaches used elevated maternal cortisol levels. The increase of maternal cortisol was achieved either by repeated injections of adrenocorticotropic hormone (ACTH) to induce increased endogenous cortisol release or by administering hydrocortisone acetate (HCA) orally. In addition, combinations of different treatments and the impact of social hierarchy in groups of pregnant sows were also studied. Table 1 gives a summary of the treatments and gestational periods determined in the different studies, where early, mid- and late gestation periods correspond roughly to day $0-38,39-76$, and $77-114$ of gestation, respectively.

\section{Effects of prenatal stress on cortisol levels}

Results from other species show that increased maternal glucocorticoid levels are a major mediator for exerting programming effects in the foetus. Thus, in pig studies, the effects of maternal treatments on sow cortisol levels in plasma or saliva were verified, either in the studies itself or in pre-experiments. Repeated oral HCA administration twice-daily or ACTH injection every second day were proven to temporarily increase maternal cortisol levels up to $8 \mathrm{~h}$ post 
Table 1: Treatments and gestational periods used in studies on prenatal stress or elevated maternal cortisol in pigs.

\begin{tabular}{|c|c|c|c|c|}
\hline \multirow[t]{2}{*}{ Treatment } & \multicolumn{3}{|c|}{ Gestation } & \multirow[t]{2}{*}{ References } \\
\hline & Period & & Days & \\
\hline \multicolumn{5}{|l|}{ Maternal stress: } \\
\hline \multirow{5}{*}{ Mixing } & Early - mid & & $24-48$ & Couret et al., 2009b \\
\hline & Mid & $\sim$ & $39-65$ & Jarvis et al., 2006; and others \\
\hline & Mid & $\sim$ & $47-68$ & Ashworth et al., 2011 \\
\hline & Late & $\sim$ & $77-103$ & Jarvis et al., 2006; and others \\
\hline & Late & $\sim$ & $77-105$ & Couret et al., 2009a,b,c; Otten et al., 2010 \\
\hline \multirow[t]{2}{*}{ Restraint } & Late & $\sim$ & $84-110$ & Otten et al., 2001; and others \\
\hline & Late & & $84-112$ & Collier et al., 2011 \\
\hline Rough handling & Mid & & $42-77$ & Lay et al., 2008; 2011 \\
\hline Heat & Late & & $100-114$ & Machado-Neto et al., 1987 \\
\hline Heat, crowding & Early - late & $\sim$ & $21-88$ & Kattesh et al., 1980 \\
\hline \multicolumn{5}{|l|}{ Increased maternal cortisol: } \\
\hline \multirow[t]{3}{*}{ Hydrocortisone acetate } & Early - mid & & $21-50$ & Kranendonk et al., 2006a,b; and others \\
\hline & Mid & & $51-80$ & Kranendonk et al., 2006a,b; and others \\
\hline & Late & & $81-110$ & Kranendonk et al., 2006a,b; and others \\
\hline \multirow[t]{3}{*}{ ACTH } & Mid & & $49-75$ & Kanitz et al., 2006; and others \\
\hline & Late & & $85-101$ & Otten et al., 2008 \\
\hline & Late & & $85-107$ & Kanitz et al., 2006; and others \\
\hline \multicolumn{5}{|l|}{ Combinations: } \\
\hline \multirow[t]{2}{*}{ ACTH + restraint } & Mid & $\sim$ & $42-77$ & Lay et al., 2008; 2011 \\
\hline & Mid & $\sim$ & $42-84$ & Haussmann et al., 2000 \\
\hline \multicolumn{5}{|l|}{ Other: } \\
\hline Social rank & Early - late & $\sim$ & $4-107$ & Kranendonk et al., 2007 \\
\hline
\end{tabular}

ACTH, adrenocorticotropic hormone

administration, without habituation over a period of several weeks (Otten et al., 2004, 2008; Kranendonk et al., 2005). Rough handling only tended to increase plasma cortisol compared to control (Lay et al., 2008). Mixing was also shown to increase salivary cortisol (Jarvis et al., 2006; Rutherford et al., 2009; Ison et al., 2010), although the magnitude of the response showed habituation over a period of repeated mixing (Couret et al., 2009a). This is probably attributed to an increasing experience of sows and a more "efficient" strategy to establish a social hierarchy as shown by the decrease in the number and duration of agonistic behaviours during later mixings (Couret et al., 2009a).

Two studies investigated the effects of maternal ACTH or HCA treatment on the foetal cortisol regulation. In foetuses recovered under general anaesthesia by Caesarean section on day 65 of gestation, increased plasma cortisol concentrations in the umbilical vein and artery, and a trend-level increase in the peripheral blood were found $3 \mathrm{~h}$ after ACTH application to the mother (Fig. 1; Otten et al., 2004). After catheterisation of a single foetus, there are indications that oral HCA administration to the mother increases the cortisol concentration in the foetal jugular vein on day 102 of gestation (Kranendonk et al., 2008). These findings indicate that maternal stress may be mediated, among other factors, by increased foetal cortisol levels either by transfer of maternal cortisol or increased foetal cortisol release. The placental enzyme $11 \beta$-hydroxysteroid dehydrogenase type 2 (11 $\beta$-HSD2) protects the foetus from excess maternal glucocorticoids and it has been shown that prenatal stress can reduce the expression and activity of placental $11 \beta-\mathrm{HSD} 2$, leading to an increased transplacental passage of active maternal glucocorticoids (Mairesse et al., 2007; Harris \& Seckl, 2011). On the other hand, 

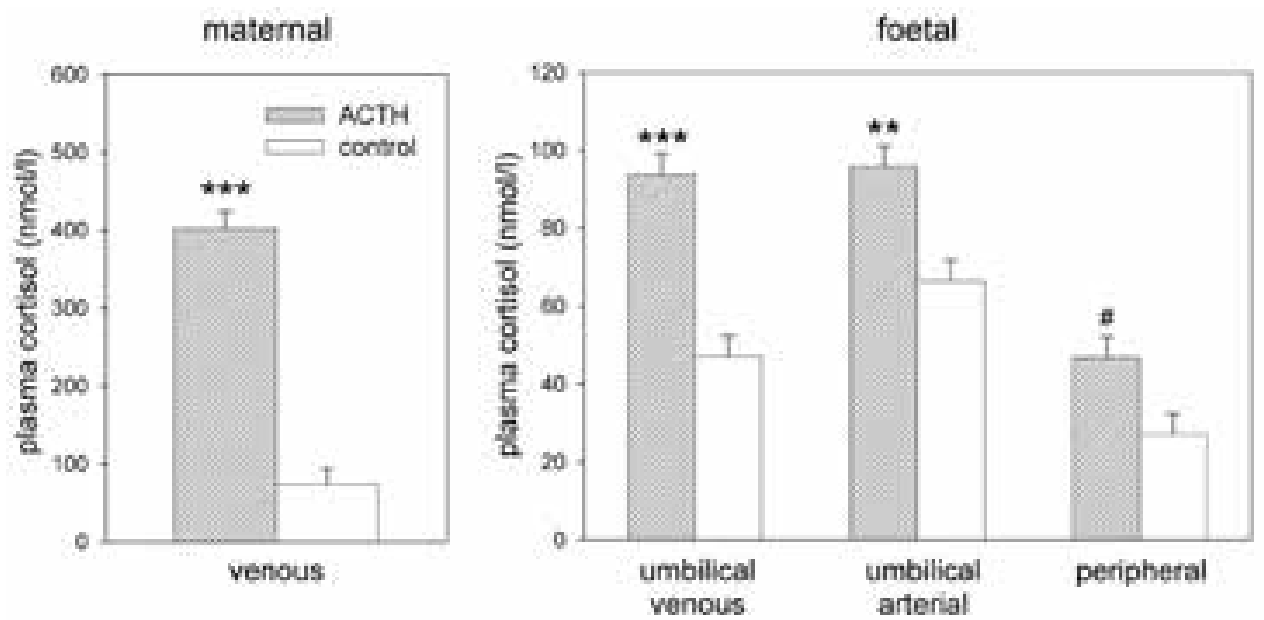

Figure 1: Plasma cortisol concentrations in sows and foetuses under general anaesthesia $3 \mathrm{~h}$ after maternal i.m. administration of $100 \mathrm{IU}$ adrenocorticotropic hormone (ACTH) (data adapted from Otten et al., 2004). ${ }^{* * * P}<0.001,{ }^{* * P}<0.01,{ }^{\#} P=0.09$

changes in placental metabolism and regulation can alter placental corticotropin-releasing hormone $(\mathrm{CRH})$ release, which in turn may increase adrenocortical activity of the foetus itself (Mulder et al., 2002).

\section{Consequences of prenatal stress on litter characteristics and growth}

All prenatal treatments used had no consequences on gestation length, litter size or proportion of males or females born. Stressful conditions like restraint, rough handling, heat or mixing of sows had no effect on birth weight of piglets and postnatal growth of the offspring. Only Jarvis et al. (2006) found a temporarily reduced growth after weaning of piglets from mothers that were repeatedly mixed during gestation, which may indicate a higher stress experienced by weaning itself. In contrast, HCA administration during early and late gestation reduced birth weights and these piglets remained lighter until weaning. At 6 months of age, however, body weight, lean meat percentage and back fat thickness did not differ (Kranendonk et al., 2006a). In one of our experiments, ACTH applications during late gestation even increased birth weight of piglets accompanied by decreased weight gain of their mothers (Otten et al., 2007). These findings may be attributed to the disturbed maternal glucose metabolism of ACTH-treated sows, which showed hyperglycaemia at the end of gestation (Otten et al., 2008). Insulin-like growth factor 1 levels of piglets did not differ after birth and the weight differences vanished until weaning (Otten et al., 2007). The percentage of live-born piglets was increased in litters of sows receiving oral HCA (Kranendonk et al., 2006a), but no effects on proportion of live or stillborn piglets or mummies were found in the other studies. Lay et al. (2008) found a reduced anogenital distance in male piglets after maternal ACTH treatment, indicating a possible demasculinisation. Thus, the results indicate that repeatedly increased maternal cortisol levels during gestation may affect foetal growth and maturation and differentiation of foetal tissues. In contrast, the experience of the different stress situations by the mother had no or only minor effects on gestation outcome and growth performance of the offspring. 


\section{Consequences of prenatal stress on immune functions and health in the offspring}

In a study by our group, we have shown that a daily 5 -min restraint stress of sows during late gestation decreased the immunoglobulin $\mathrm{G}(\lg \mathrm{G})$ concentrations in serum of neonatal pigs, had an immunosuppressive effect on mitogen-induced lymphocyte proliferation, reduced the relative thymus weights in piglets on days 1 and 35 of life and increased the morbidity and mortality of offspring during the suckling period (Otten et al., 2001; Tuchscherer et al., 2002). A repeated $\mathrm{ACTH}$ stimulation of sows during late gestation also decreased the lymphocyte proliferative response in new-born piglets, but not when applied during mid-gestation (Otten et al., 2007). Furthermore, heat stress in late pregnancy resulted in piglets with decreased IgG levels and increased pre-weaning mortality (Machado-Neto et al., 1987). Together these findings emphasize the impact of maternal stress during late pregnancy on the health and vitality of the offspring in pigs (Table 2).

Table 2: Effects of different gestational periods and prenatal treatments on offspring characteristics in pigs (combined data from different prenatal stress studies in pigs).

\begin{tabular}{|c|c|c|c|c|c|c|c|c|}
\hline $\begin{array}{l}\text { Gestation } \\
\text { period }\end{array}$ & Treatment & $\begin{array}{c}\text { Birth } \\
\text { weight }\end{array}$ & $\begin{array}{l}\text { Postnatal } \\
\text { growth }\end{array}$ & $\begin{array}{l}H P A \\
\text { regulation }\end{array}$ & $\begin{array}{c}\text { Neuro- } \\
\text { transmitter }\end{array}$ & Behaviour & $\begin{array}{l}\text { Immune } \\
\text { function }\end{array}$ & References \\
\hline $\begin{array}{l}\text { Early - } \\
\text { mid }\end{array}$ & $\mathrm{HCA}$ & $x$ & - & $x$ & . & $x$ & $x$ & $\begin{array}{l}\text { Kranendonk et al. } \\
2006 a, b ; \text { de Groot et al., } \\
2007\end{array}$ \\
\hline $\begin{array}{l}\text { Early - } \\
\text { mid }\end{array}$ & Mixing & - & - & - & . & . & - & Couret et al., 2009b \\
\hline Mid & ACTH & - & - & $x$ & $x$ & - & - & $\begin{array}{l}\text { Kanitz et al., 2006; Otten } \\
\text { et al., } 2007\end{array}$ \\
\hline Mid & $\mathrm{HCA}$ & - & - & - & . & $x$ & - & $\begin{array}{l}\text { Kranendonk et al. } \\
2006 a, b ; \text { de Groot et al., } \\
2007\end{array}$ \\
\hline Mid & Mixing & - & $x$ & $x$ & • & $x$ & . & $\begin{array}{l}\text { Jarvis et al., 2006; } \\
\text { Rutherford et al., 2009; } \\
\text { Ashworth et al., } 2011\end{array}$ \\
\hline Mid & $\begin{array}{l}\text { Rough } \\
\text { handling }\end{array}$ & - & - & - & . & $x$ & - & Lay et al., 2008; 2011 \\
\hline Mid & $\begin{array}{l}\mathrm{ACTH}+ \\
\text { restraint }\end{array}$ & - & - & $x$ & . & $x$ & $x$ & $\begin{array}{l}\text { Haussmann et al., 2000; } \\
\text { Lay et al., 2008; } 2011\end{array}$ \\
\hline Late & $\mathrm{ACTH}$ & $x$ & - & $x$ & $x$ & $x$ & $x$ & $\begin{array}{l}\text { Kanitz et al., 2006; Otten } \\
\text { et al., 2007; } 2008\end{array}$ \\
\hline Late & $\mathrm{HCA}$ & $x$ & - & $x$ & . & $x$ & $x$ & $\begin{array}{l}\text { Kranendonk et al. } \\
2006 a, b ; \text { de Groot et al., } \\
2007\end{array}$ \\
\hline Late & Mixing & - & $x$ & $x$ & $x$ & $x$ & $x$ & $\begin{array}{l}\text { Jarvis et al., 2006; Couret } \\
\text { et al., 2009a,b,c; Otten et } \\
\text { al., } 2010\end{array}$ \\
\hline Late & Restraint & - & - & $x$ & - & . & $x$ & $\begin{array}{l}\text { Otten et al., 2001; } \\
\text { Tuchscherer et al., 2002; } \\
\text { Kanitz et al, 2003; Collier } \\
\text { et al., } 2011\end{array}$ \\
\hline
\end{tabular}

" $\times$ ", significant effect; "-“, no effect; ".", not studied; HCA, hydrocortisone acetate; ACTH, adrenocorticotropic hormone 
On the other hand, repeated mixing stress applied to pregnant sows during late gestation has only moderate but long-lasting effects on immune responses in offspring (Couret et al., $2009 b, c)$. Prenatally stressed piglets displayed decreased blood cell counts and an increased ability of lymphocytes to proliferate until two months of age. However, neither pre-weaning mortality nor thymus and spleen weights in suckling and weaned piglets were affected by prenatal stress. The same social stress procedure during early gestation had no effects on the immune system of the piglets (Couret et al., 2009b).

A combination of restraint and ACTH injection (Haussmann et al., 2000; Lay et al., 2011) during mid-gestation was shown to reduce the healing rate of punch wounds in the offspring. To date, there is little evidence in pigs detailing effects of maternal stress on immune responses of offspring to stressful stimuli. Oral HCA during the first and third period of gestation provoked a higher fever response to lipopolysaccharide (LPS) in piglets, whereas the latency time in a human approach test after LPS was reduced in offspring exposed to mid-gestation treatment (De Groot et al., 2007). The last result is in agreement with findings of Lay et al. (2011) after rough handling during mid-gestation indicating a shorter duration of LPS-induced sickness behaviour. Maternal restraint stress during late gestation enhanced the magnitude of interleukin 6 and serum amyloid responses to LPS in the offspring (Collier et al., 2011). On the other hand, plasma tumour necrosis factor-alpha (TNF $\alpha$ ) levels and interleukin 6 mRNA expression in the liver of piglets after LPS administration were not influenced by early or late social gestational stress (Couret et al., 2009b). In addition, both maternal ACTH and rough treatments in midgestation did not affect the response of offspring to mixing stress with regard to haematological measures, antibodies against a foreign antigen and nitric oxide production of macrophages (Lay et al., 2011). Thus, it seems that prenatal stress may cause alterations in the sensitivity to an immune challenge in pigs depending on the type of stressor and challenge used.

Further, results also suggest that the effects of maternal stress can be sex-specific. For example, the increased proliferation of blood and spleen lymphocytes was more pronounced in female offspring exposed to mixing stress during late gestation (Couret et al., 2009b). Castrated males born to restraint-stressed sows had a lower peak of TNF $\alpha$ concentration to LPS than non-stressed animals at five weeks of age, while this response in female pigs was not influenced by maternal stress (Collier et al., 2011). Studies in rodents have shown that sex-specific programming during pregnancy can be caused by changes in maternal steroid levels and subsequent suppression of foetal testosterone concentrations (Ward \& Weisz, 1984), and/or by different expression of growth factors and nutrient transporter genes in the placenta of males and females (Mueller \& Bale, 2008). In summary, the studies suggest that prenatal stress can affect immunological development as well as humoral and cellular immune functions in offspring and thereby may alter the susceptibility to diseases.

\section{Consequences of prenatal stress on neuroendocrine functions and behaviour in the offspring}

It was shown in laboratory animals that prenatal stress may cause structural and functional effects on HPA axis, neurotransmitter systems and behaviour in the offspring, and that many of these effects are mediated by glucocorticoids. In pigs, offspring of mothers subjected to daily restraint stress during late gestation showed lower basal plasma cortisol and increased corticosteroid binding globulin (CBG) concentrations at day 3 of age (Otten et al., 2001; Kanitz et al., 2003). Furthermore, prenatally stressed piglets exhibited reduced hypothalamic glucocorticoid receptor (GR) binding sites but increased hippocampal GR binding sites with no effect on the hippocampal mineralocorticoid receptor, possibly indicating decreased negative 
feedback at the hypothalamic paraventricular nucleus (PVN) and enhanced facilitation of the HPA response (Kanitz et al., 2003).

Stimulation of maternal cortisol release by weekly ACTH application in combination with restraint during mid-gestation resulted in offspring with higher adrenocortical expression of $\mathrm{ACTH}$ receptor $\mathrm{mRNA}$ and a higher adrenal cortex:medulla area ratio at day 1 of age; the ratio also persisted to 60 days of age, indicating greater adrenal sensitivity. At 30 days of age, prenatally stressed piglets had lower $\beta$-endorphin and tended to have higher $\mathrm{CRH}$ concentrations in the hypothalamus, and at 60 days of age, these pigs showed a higher expression of pituitary pro-opiomelanocortin mRNA. Under stressful conditions (mixing), pigs in the maternal ACTHtreated group also showed a higher plasma cortisol response which points to a hyperactive HPA axis in the offspring (Haussmann et al., 2000). On the other hand, a treatment of pregnant sows with $\mathrm{ACTH}$ alone every two days during mid-gestation increased the expression of c-fos but not of CRH mRNA in the foetal brain and decreased ACTH receptor mRNA in the adrenal gland of foetuses (Schwerin et al., 2005). The same ACTH model applied in pigs during late gestation increased hippocampal serotonergic activity in foetuses of ACTH-treated sows as shown by elevated 5-hydroxytryptamine levels, which may have consequences for the emotional reactivity and coping behaviour of the offspring later in life (Otten et al., 2008). The repeated ACTH treatment during both mid- and late gestation caused a decrease of plasma CBG in suckling piglets. Administration of ACTH during mid-gestation increased the noradrenergic activity in the locus coeruleus (LC) of piglets, whereas ACTH treatment during late gestation increased plasma noradrenaline concentrations and decreased serotonergic activity in the LC. Furthermore, there were sex-specific effects of ACTH treatment on plasma CBG, noradrenaline and brain monoamine turnover, with more pronounced changes in male offspring (Kanitz et al., 2006).

This and other studies show that the effects of prenatal stress on HPA axis regulation and neurotransmitter systems in the offspring are dependent on the timing of exposure. Offspring ( 6 weeks old) whose mothers were treated with HCA during mid-gestation exhibited elevated basal salivary cortisol levels, while those exposed during early and late gestation exhibited normal basal cortisol but attenuated responses to an ACTH challenge (Kranendonk et al., 2006a). Couret et al. (2009b) found a reduction of relative adrenal weight in prenatally stressed piglets at 5 days of age when the social stress was applied during early gestation. In contrast, social stress during late gestation increased relative adrenal weights at 4 days and cell density in the cortex and medulla at 28 days of age (Otten et al., 2010).

Central sites of the HPA axis and the limbic system seem to be specifically vulnerable to prenatal stress effects. Social stress during mid- or late gestation increased CRH mRNA expression in the amygdala, and social stress during mid-gestation also in the PVN of female offspring. Both groups showed an increased HPA reactivity with enhanced salivary cortisol levels after a mixing challenge at 67 days of age (Jarvis et al., 2006). Prenatal social stress during mid-and late gestation together also increased $\mathrm{CRH}$ mRNA expression in the PVN and amygdala after acute restraint stress (Ison et al., 2010). Furthermore, it was shown that maternal social stress during late gestation decreased the basal CBG concentration before weaning and increased the hippocampal serotonergic activity and expression of $11 \beta-H S D 1$ mRNA after weaning. In addition, expression of $11 \beta$-HSD1 mRNA tended to be increased and hippocampal c-fos mRNA expression and noradrenalin concentration was increased after relocation at 62 days of age (Fig. 2; Otten et al., 2010). Together, the results indicate that both maternal stress and elevated maternal cortisol levels have profound influences on neuroendocrine regulation within the amygdala, hippocampus and hypothalamus of offspring in pigs, and also seem to modify the HPA reactivity in stressful situations. However, differences were found in the phenotype of offspring between glucocorticoid (ACTH, HCA) and maternal stress models. These may be 


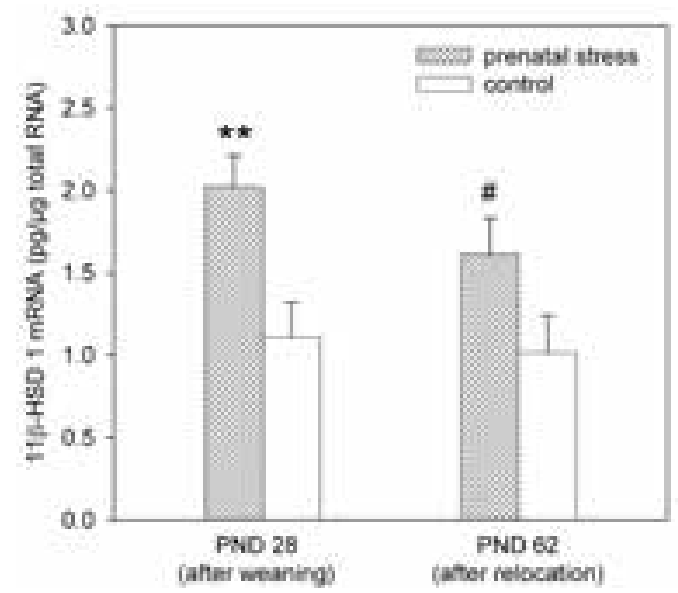

Figure 2: Effects of repeated social stress during late gestation on hippocampal 11ß-hydroxysteroid dehydrogenase 1 (11ß-HSD1) mRNA expression in offspring 2 days after weaning and relocation on postnatal days (PND) 28 and 62, respectively (data adapted from Otten et al., 2010). ${ }^{*} P P<0.01$, ${ }^{\#} P=0.08$

caused by differences in the experimental protocols, affecting the magnitude of the cortisol response, but might also suggest that there are glucocorticoid-independent mechanisms involved in the mediation of maternal stress to the foetus. In the maternal stress models, various endocrine changes go along with the stress response, including catecholamine release and action of further steroid hormones and growth factors. These may directly affect foetal gene expression or indirectly act on foetal development by an altered placental metabolism and regulation, blood flow and redistribution of nutrients (Harris \& Seckl, 2011).

Alterations of neuroendocrine set points in the limbic and HPA system of prenatally stressed offspring might also affect their social and anxiety-related behaviour. Therefore, several studies investigated behavioural characteristics of the offspring in the home pen and in relation to challenging situations such as weaning and mixing or during a novel environment or a novel object test. Piglets from HCA-treated sows were found to spend less time in social interactions in the home pen and performed less individual play behaviour and social behaviour after weaning (Kranendonk et al., 2006b). During a novel-environment test, offspring from sows with increased cortisol levels during gestation showed more locomotion, vocalisations (Kranendonk et al., 2006b) and escape attempts (Otten et al., 2007), reflecting an increased emotional reactivity. Social stress during gestation also affected the coping of the offspring with a new environment. After weaning, subtle changes in aggressive behaviour occurred, and more retreats and more nosing were observed even 7 days later, indicating a delayed return to a stable social group (Jarvis et al., 2006). Sub-dominance of sows during gestation decreased locomotion and vocalisation of offspring in a new environment, and increased the latency time to touch a novel object (Kranendonk et al., 2007). Accordingly, increased social stress, as indicated by a higher lesion score of sows, was found to reduce activity, vocalisations and aggression after weaning (Ison et al., 2010). Interestingly, the studies suggest that elevated maternal cortisol levels alone may result in offspring with increased emotional reactivity in a novel environment, whereas offspring from psychologically stressed sows showed more anxiety and depressive-like behaviour. These behavioural differences may be determined by the different physiological stress responses of the mother, amongst others, e.g. by different sympatho-adrenomedullary activation, and require further investigation.

\section{Implications}

Present studies demonstrate that maternal stress in pigs may have profound consequences on physiology and behaviour in the offspring. In other animal models and in humans it was 
shown that glucocorticoids are a major transmitter mediating the effects of maternal stress upon the developing foetus. There is also evidence in pigs that an increase of maternal cortisol is associated with foetal cortisol overexposure. Cortisol has a crucial role during normal foetal development and binds to specific receptors which act as transcription factors and alter gene expression. Thus, excess or deficient cortisol signalling during critical windows of development may have subtle or drastic changes in organ maturation, brain development and function.

In pigs, mid- and even more pronounced late, gestation appear to be sensitive periods for programming effects of prenatal stress, affecting HPA axis regulation, behaviour and immune functions in the offspring (Table 2). These periods coincide with the maturation of the foetal HPA axis, establishment of immunocompetent cells and growth spurt. In contrast, gestation outcome and proportion of male and females born were not affected. Experimental models using artificially elevated maternal cortisol reveal effects on birth weight proving the role of cortisol in foetal development and maturation. On the other hand, repeated stress experienced by the mother had no or only minor effects on body weight of the offspring, which may be explained by a lower magnitude or habituation of the cortisol response and individual differences in the perception of the stressor. Although the results are inconsistent, it appears that immune functions in the offspring may be impaired by late gestational stress, which can result in a reduced vitality of piglets. As expected from other species, the HPA axis and limbic system including hippocampus and amygdala seem to be particularly sensitive to altered cortisol levels during development. Neuroendocrine and behavioural results indicate that prenatally stressed pigs can express an over-reactive phenotype characterised by an increased HPA axis reactivity, altered emotionality, more fearfulness in a novel environment and disturbed social behaviour, where the specific phenotype depends on whether a maternal stress or glucocorticoid model was used. These behavioural consequences are of particular importance for female offspring used for breeding because they may have a negative impact on their maternal behaviour as indicated by the findings of Jarvis et al. (2006). Moreover, because only few studies investigated prenatal stress effects on reproductive performance in the offspring of pigs (Brüssow et al., 2005; Ashworth et al., 2011), future research should focus on the long-term consequences relevant for reproductive traits, maternal behaviour and immune function in female offspring used for breeding.

\section{References}

Ashworth CJ, Hogg CO, Hoeks CW, Donald RD, Duncan WC, Lawrence AB \& Rutherford KM 2011 Pre-natal social stress and post-natal pain affect the developing pig reproductive axis. Reproduction 142 907-914.

Barbazanges A, Piazza, PV, Le Moal M \& Maccari, S 1996 Maternal glucocorticoid secretion mediates long-term effects of prenatal stress. Journal of Neuroscience $\mathbf{1 6}$ 3943-3949.

Brüssow KP, Schneider F, Kanitz E, Otten W \& Tuchscherer M 2005 Alteration of reproductive hormone levels in pregnant sows induced by repeated ACTH application and its possible influence on preand post-natal hormone secretion of piglets. Journal of Reproduction and Development 51 133-142.

Collier CT, Williams PN, Carroll JA, Welsh Jr. TH \& Laurenz JC 2011 Effect of maternal restraint stress during gestation on temporal lipopolysaccharideinduced neuroendocrine and immune responses of progeny. Domestic Animal Endocrinology 40 40-50.
Couret D, Otten W, Puppe B, Prunier A \& Merlot E 2009a Behavioural, endocrine and immune responses to repeated social stress in pregnant gilts. Animal $\mathbf{3}$ 118-127.

Couret D, Prunier A, Mounier AM, Thomas F, Oswald IP \& Merlot E 2009b Comparative effects of a prenatal stress occurring during early or late gestation on pig immune response. Physiology \& Behavior 98 498-504.

Couret D, Jamin A, Kuntz-Simon G, Prunier A \& Merlot E 2009C Maternal stress during late gestation has moderate but long-lasting effects on the immune system of the piglets. Veterinary Immunology and Immunopathology 131 17-24.

De Groot J, Kranendonk G, Fillerup $M$, Hopster $\mathbf{H}$, Boersma W, Hodgson D, Van Reenen K \& Taverne M 2007 Response to LPS in female offspring from sows treated with cortisol during pregnancy. Physiology \& Behavior 90 612-618.

Fowden AL \& Forhead AJ 2004 Endocrine mechanisms 
of intrauterine programming. Reproduction 127 515526.

Harris A \& Seckl J 2011 Glucocorticoids, prenatal stress and the programming of disease. Hormones and Behavior 59 279-289.

Haussmann MF, Carroll JA, Weesner GD, Daniels MJ, Matteri RL \& Lay Jr. DC 2000 Administration of ACTH to restrained, pregnant sows alters their pigs' hypothalamic-pituitary-adrenal (HPA) axis. Journal of Animal Science 78 2399-2411.

Ison SH, D'Eath RB, Robson SK, Baxter EM, Ormandy E, Douglas AJ, Russell JA, Lawrence AB \& Jarvis S 2010 'Subordination style' in pigs? The response of pregnant sows to mixing stress affects their offspring's behavior and stress reactivity. Applied Animal Behaviour Science 124 16-27.

Jarvis S, Moinard C, Robson SK, Baxter E, Ormandy E, Douglas AJ, Seckl JR, Russell JA \& Lawrence AB 2006 Programming the offspring of the pig by prenatal social stress: neuroendocrine activity and behaviour. Hormones and Behavior 49 68-80.

Kanitz E, Otten W, Tuchscherer M \& Manteuffel G 2003 Effects of prenatal stress on corticosteroid receptors and monoamine concentrations in limbic areas of suckling piglets (Sus scrofa) at different ages. Journal of Veterinary Medicine Series A-Physiology Pathology Clinical Medicine 50 132-139.

Kanitz E, Otten W \& Tuchscherer M 2006 Changes in endocrine and neurochemical profiles in neonatal pigs prenatally exposed to increased maternal cortisol. Journal of Endocrinology 191 207-220.

Kattesh HG, Kornegay ET, Knight JW, Gwazdauskas FG, Thomas HR \& Notter DR 1980 Glucocorticoid concentrations, corticosteroid binding protein characteristics and reproduction performance of sows and gilts subjected to applied stress during mid-gestation. Journal of Animal Science 50 897-905.

Kranendonk G, Hopster H, Van Eerdenburg F, Van Reenen K, Fillerup M, De Groot J, Korte M \& Taverne M 2005 Evaluation of oral administration of cortisol as a model for prenatal stress in pregnant sows. American Journal of Veterinary Research 66 780-790.

Kranendonk G, Hopster H, Fillerup M, Ekkel ED, Mulder EJ, Wiegant VM \& Taverne MA 2006a Lower birth weight and attenuated adrenocortical response to $\mathrm{ACTH}$ in offspring from sows that orally received cortisol during gestation. Domestic Animal Endocrinology 30 218-238.

Kranendonk G, Hopster H, Fillerup M, Ekkel ED, Mulder EJ \& Taverne MA $2006 b$ Cortisol administration to pregnant sows affects novelty-induced locomotion, aggressive behaviour, and blunts gender differences in their offspring. Hormones and Behavior 49 663-672.

Kranendonk G, Van der Mheen H, Fillerup M \& Hopster H 2007 Social rank of pregnant sows affects their body weight gain and behavior and performance of the offspring. Journal of Animal Science 85 420-429.

Kranendonk G, Mulder EJ, Parvizi N \& Taverne MA 2008 Prenatal stress in pigs: experimental approaches and field observations. Experimental and Clinical Endocrinology \& Diabetes 116 413-422.
Lay Jr. DC, Kattesh HG, Cunnick JE, Daniels MJ, McMunn KA, Toscano MJ \& Roberts MP 2008 Prenatal stress effects on pig development and response to weaning. Journal of Animal Science 86 1316-1324.

Lay Jr. DC, Kattesh HG, Cunnick JE, Daniels MJ, Kranendonk G, McMunn KA, Toscano MJ \& Roberts MP 2011 Effect of prenatal stress on subsequent response to mixing stress and a lipopolysaccharide challenge in pigs. Journal of Animal Science $\mathbf{8 9}$ 1787-1794.

Machado-Neto R, Graves CN \& Curtis SE 1987 Immunoglobulins in piglets from sows heat-stressed prepartum. Journal of Animal Science 65 445-455.

Mairesse J, Lesage J, Breton C, Bréant B, Hahn T, Darnaudéry $M$, Dickson SL, Seckl J, Blondeau B, Vieau D et al. 2007 Maternal stress alters endocrine function of the feto-placental unit in rats. American Journal of Physiology - Endocrinology and Metabolism 292 E1526-E1533.

Merlot E, Couret D \& Otten W 2008 Prenatal stress, fetal imprinting and immunity. Brain, Behavior, and Immunity 22 42-51.

Mueller BR \& Bale TL 2008 Sex-specific programming of offspring emotionality after stress early in pregnancy. Journal of Neuroscience 28 9055-9065.

Mulder EJ, Robles de Medina PG, Huizink AC, Van den Bergh BR, Buitelaar JK \& Visser GH 2002 Prenatal maternal stress: effects on pregnancy and the (unborn) child. Early Human Development 70 3-14.

Otten W, Kanitz E, Tuchscherer M \& Nürnberg G 2001 Effects of prenatal restraint stress on hypothalamic-pituitary-adrenocortical and sympathoadrenomedullary axis in neonatal pigs. Animal Science 73 279-287.

Otten W, Kanitz E, Tuchscherer M, Schneider F \& Brüssow KP 2004 Effects of adrenocorticotropin stimulation on cortisol dynamics of pregnant gilts and their fetuses: implications for prenatal stress studies. Theriogenology 61 1649-1659.

Otten W, Kanitz E, Tuchscherer M, Puppe B \& Nürnberg G 2007 Repeated administrations of adrenocorticotropic hormone during gestation in gilts: Effects on growth, behaviour and immune responses of their piglets. Livestock Science 106 261-270.

Otten W, Kanitz E, Tuchscherer M, Brüssow KP \& Nürnberg G 2008 Repeated administrations of adrenocorticotropic hormone during late gestation in pigs: maternal cortisol response and effects on fetal HPA axis and brain neurotransmitter systems. Theriogenology 69 312-322.

Otten W, Kanitz E, Couret D, Veissier I, Prunier A \& Merlot E 2010 Maternal social stress during late pregnancy affects hypothalamic-pituitary-adrenal function and brain neurotransmitter systems in pig offspring. Domestic Animal Endocrinology 38 146156.

Rutherford KM, Robson SK, Donald RD, Jarvis S, Sandercock DA, Scott EM, Nolan AM \& Lawrence AB 2009 Pre-natal stress amplifies the immediate behavioural responses to acute pain in piglets. Biology Letters 5 452-454. 
Schwerin M, Kanitz E, Tuchscherer M, Brüssow KP, Nürnberg G \& Otten W 2005 Stress-related gene expression in brain and adrenal gland of porcine fetuses and neonates. Theriogenology 63 1220-1234.

Tuchscherer M, Kanitz E, Otten W \& Tuchscherer A 2002 Effects of prenatal stress on cellular and humoral immune responses in neonatal pigs. Veterinary Immunology and Immunopathology 86 195-203.
Viltart O \& Vanbesien-Mailliot CCA 2007 Impact of prenatal stress on neuroendocrine programming. The Scientific World Journal 7 1493-1537.

Ward IL \& Weisz J 1984 Differential effects of maternal stress on circulating levels of corticosterone, progesterone, and testosterone in male and female rat fetuses and their mothers. Endocrinology 114 1635-1644. 
